\title{
PHILetegiteA
}

Philologica Canariensia 23 (2017), pp. 33-48 eISSN: 2386-8635

DOI: 10.20420/PhilCan.2017.147

Recibido: 11 de abril de 2017; versión revisada aceptada: 12 de junio de 2017

Publicado: 26 de junio de 2017

\section{ANÁLISIS DEL LÉXICO RELACIONADO CON LA MONOPARENTALIDAD FEMENINA EN UN CORPUS DE PRENSA DIGITAL ESPAÑOLA}

\author{
ESTEFANÍA FLORES ACUÑA \\ Universidad Pablo de Olavide
}

\begin{abstract}
RESUMEN: El presente artículo constituye un análisis de aquellas lexías que consideramos más representativas de las situaciones de monoparentalidad protagonizadas por una mujer en el discurso mediático generado en España en las tres últimas décadas. Utilizaremos para ello un corpus específico conformado por textos extraídos de cuatro diarios españoles disponibles en versión digital, el cual nos aportará datos de distinta naturaleza sobre el uso discursivo de las unidades léxicas analizadas y nos permitirá comprobar cómo influye la prensa en la imagen estereotipada que se pueda tener de este modelo de familia. Entre las conclusiones obtenidas, cabe destacar la mayor visibilidad y menor ocultamiento social del fenómeno en el último bienio analizado, la evolución en el tipo de temáticas donde dicho modelo familiar adquiere relevancia, así como la asociación de determinadas lexías con exclusión social y pobreza, y de otras, en cambio, con empoderamiento femenino.
\end{abstract}

PALABRAS CLAVE: monoparentalidad femenina, madre soltera, estereotipos sociales, lingüística de corpus, prensa española

Lexical discourse analysis of the single-motherhood phenomenon through a corpus-based study of digitized newspapers

\begin{abstract}
This article analyzes the structures of single-parent families headed by women by focusing on the discourse of the media in Spain over the last thirty years. This goal will be reached through a corpus-based study that will provide data, from the quantitative and qualitative point of view, on the selected lexical items. This study will enable us to examine to what extent the Spanish press contributes to stereotype this kind of family model. Amongst our conclusions are: (1) in the last analyzed biennium, a greater visibility and less social concealment of the phenomenon has been revealed; (2) over time there was some change in the kind of issues related to this family model; and (3) certain lexical items have been traditionally associated with social exclusion and poverty, whereas other lexical items have been associated with women's empowerment.
\end{abstract}

KEYWORDS: single motherhood, single mother, social stereotypes, corpus linguistics, Spanish press

\section{INTRODUCCIÓN}

Una tarea imprescindible en la necesaria revisión de los modelos teóricos que han analizado las realidades familiares en las diversas sociedades a lo largo del tiempo es, sin duda, una reflexión lingüística que contribuya a poner de manifiesto cómo la representación verbal de dichas realidades puede influir decisivamente en los planos administrativo, político o social. ${ }^{1}$ Esta reflexión ya ha comenzado gracias a contribuciones como las de Hays (1998) sobre los mensajes que reciben las madres acerca de cuál ha de ser su comportamiento en el ámbito personal y laboral; las investigaciones de Medina Bravo, Figueras-Maz y Gómez-Puertas (2014) sobre el modelo de maternidad intensiva 
reflejado en el discurso de las revistas de familia; los estudios de Rodríguez Barcia (2014) donde se identifican las estrategias semánticas globales utilizadas en las revistas de familia para la consolidación de los roles sociales masculino y femenino, o la contribución de Milkie y Denny sobre cómo el discurso utilizado en las revistas dirigidas a los progenitores refleja el modelo cultural de implicación de la figura paterna en la crianza del bebé. Todas estas investigaciones podrían enmarcarse en el denominado análisis crítico del discurso, enfoque multidisciplinar que, tal y como lo describe Van Dijk (1999, 2002, 2003), "se centra en los problemas sociales, y en especial en el papel del discurso en la producción y en la reproducción del abuso de poder o de la dominación” $(2003,144)$.

En este trabajo, partimos de una revisión crítica previa (Flores Acuña, 2017) en la que analizamos la relación léxico-sociedad centrándonos en el campo de las conformaciones familiares monoparentales encabezadas por una mujer. ${ }^{2}$ La monoparentalidad, concebida como núcleo familiar formado por un único progenitor y uno o más hijos, es un fenómeno multiforme resultado de una larga serie de factores. Ante una sociedad donde la familia monoparental ha sido tradicionalmente considerada como la antítesis de la familia convencional, y convencidos de que en la creación y consolidación de estereotipos sociales los medios de comunicación desempeñan un papel decisivo, en este artículo nos hemos propuesto comprobar la visión que sobre este fenómeno ofrece la prensa generalista española. Plantearemos el análisis de aquellas lexías que son más representativas de las situaciones de monoparentalidad protagonizadas por una mujer, utilizando para ello un corpus específico conformado por textos extraídos de cuatro diarios españoles disponibles en versión digital y de línea editorial muy diferente entre sí.

La interpretación lingüística de los datos, tanto desde una perspectiva cualitativa como cuantitativa, será indisociable de la lectura sociológica. Ello nos permitirá, al mismo tiempo, comprobar en qué medida el tratamiento que hace la prensa de este modelo de familia contribuye a la imagen estereotipada que de ella se pueda tener en nuestro país en las tres últimas décadas y a la (in)visibilidad de las diversas modalidades de monoparentalidad existentes.

\section{MATERIALES Y MÉTODO}

En Flores Acuña $(2017,21)$ presentábamos un breve estudio semasiológico de las lexías complejas madre soltera, madre soltera por elección, madre sola, madre sola por elección y madre adolescente. 3 Este corpus léxico fue elaborado extrayendo aquellas lexías que, tras la revisión del marco teórico existente sobre el tema, consideramos más representativas de las situaciones de monoparentalidad que cumplen los siguientes tres criterios: sexo del progenitor (mujeres), edad (adolescentes/adultos), y ruta de entrada a la monoparentalidad (interrupción de un proyecto familiar / decisión libre y voluntaria de la mujer):

\begin{tabular}{|l|c|c|c|c|}
\hline \multicolumn{1}{|c|}{ Lexemas Semas } & S1 & S2 & S3 & S4 \\
\hline Madre soltera & + & + & + & - \\
\hline Madre soltera por elección & + & + & + & - \\
\hline Madre sola & + & - & + & - \\
\hline Madre sola por elección & + & - & + & - \\
\hline Madre adolescente & + & - & - & + \\
\hline
\end{tabular}




\begin{tabular}{|l|}
\hline LEYENDA \\
\hline S1: Es madre. \\
S2: Necesariamente no está casada. \\
S3: No cohabita con pareja sentimental. \\
S4: Necesariamente no supera los 18 años. \\
\hline
\end{tabular}

Tabla 1. Semas lexías complejas (Flores Acuña, 2017, 21)

En el presente trabajo localizaremos las cinco unidades léxicas seleccionadas en un corpus de textos extraídos de los cuatro primeros diarios españoles desde la década de los noventa hasta la segunda década del siglo XXI. Hemos elegido la prensa generalista por ser en este medio donde suelen tratarse los principales temas de interés político, económico y social de alcance nacional e internacional, de forma que constituye un buen observatorio de los cambios y neologismos que se introducen en una lengua. ${ }^{4}$ En concreto, hemos extraído nuestro corpus de los cuatro diarios de tirada nacional más importantes según número de lectores en España, todos ellos de línea editorial diferente: El País (EP), ${ }^{5}$ El Mundo (EM), ${ }^{6}$ La Vanguardia (LV), ${ }^{7}$ y $A B C$ (ABC). ${ }^{8}$

Con el fin de adoptar, al mismo tiempo, una perspectiva diacrónica, hemos realizado una cala en nuestro corpus que abarca tres décadas diferentes (1993/94, 2003/04, 2013/14). ${ }^{9} \mathrm{El}$ rastreo en los motores de búsqueda de los archivos electrónicos de estos diarios nos ha permitido configurar un corpus formado únicamente por aquellos textos - procedentes de cualquier sección del periódico, pues no hemos discriminado por géneros periodísticos- en que las lexías que nos interesan aparecen al menos una vez. Es importante aclarar que en la tabla de frecuencias no aparecerá el número real de ocurrencias de las lexías en el corpus, pues no contaremos ocurrencias totales sino ocurrencias por texto, es decir, si en un mismo texto la lexía se repite, no la contaremos más de una vez. Esto es así porque nuestro interés se centra en descubrir en qué medida, en qué temáticas y con cuáles expresiones los textos periodísticos abordan la monoparentalidad femenina, para lo cual no resulta relevante que una misma lexía se repita más o menos veces dentro de un mismo texto. Tampoco distinguiremos entre singular y plural en el recuento: la aparición en el mismo texto de madre soltera y madres solteras contará como una única unidad. Excluimos asimismo de nuestro recuento aquellos casos de concurrencia de los mismos elementos de nuestras lexías pero sin componer lexía compleja: "madre y soltera", "su madre, soltera y sin recursos", "dejó a su madre sola", etc.

Pretendemos llevar a cabo un análisis transversal y longitudinal que nos permita obtener conclusiones de tipo cuantitativo (frecuencia de las distintas lexías, presencia de lexías emergentes frente a la presencia residual o la desaparición de lexías caídas en desuso) y cualitativo (protagonismo concedido a alguno de los subtipos de monoparentalidad estudiados, identificación de las áreas temáticas en que se concentran las lexías, carga connotativa en el uso de las lexías, relación línea editorial del periódico con áreas temáticas identificadas, etc.). La cala seleccionada nos permite asimismo obtener una perspectiva sincrónica (comparación entre frecuencias de distintas lexías en un mismo periodo, diferencias entre periódicos en el mayor o menor uso de lexías y posible motivación ideológica, relación entre la frecuencia de lexías y acontecimientos de la actualidad de ese periodo) y diacrónica (crecimiento o retroceso en el uso de las lexías a lo largo del tiempo, asunción o pérdida de connotaciones semánticas por parte de una misma lexía, razones por 
las que se crea una nueva lexía o deja de utilizarse otra ya existente, desplazamiento de las áreas semánticas preferentes para determinados usos, etc.).

\section{RESULTADOS}

Antes de exponer los datos obtenidos tras el análisis del corpus de prensa seleccionado, y habida cuenta de la interpretación cualitativa que pretendemos efectuar, resulta obligado presentar las categorías temáticas que hemos establecido para clasificar los textos donde aparecen las lexías objeto de interés. Como ya apuntábamos más arriba, no hemos querido distinguir entre géneros informativos, de opinión o interpretativos, ni tampoco excluir secciones como cultura, cartelera, programación de televisión, etc. Ello se debe a que hemos considerado más relevante para nuestro estudio el hilo argumental principal del texto, teniendo presente ante todo la pertinencia de la alusión a la monoparentalidad en el contexto global, independientemente del género a que corresponda o de la sección en que haya sido publicado. Quiere esto decir que, si en una noticia de sucesos se hace referencia al hecho de que el implicado era hijo de madre soltera, clasificaremos este texto entre los vinculados a la biografía de anónimos, pues es este dato y no otro el que nos interesa para nuestro análisis.

Somos conscientes de la inevitable subjetividad que implica un proceso como este, pues los límites entre temáticas no siempre son nítidos: noticias sobre desahucios de madres solteras, por ejemplo, podrían ser encuadradas entre los textos de economía, pero también en los de sociedad. De nuevo, el criterio que se ha impuesto para la clasificación ha sido el papel que desempeña el dato sobre la monoparentalidad en el conjunto de la información ofrecida.

Listamos a continuación las categorías que hemos establecido junto con una breve descripción de las temáticas a las que darían cabida:

a) Biografias: vida de personajes famosos con algún episodio de monoparentalidad femenina; datos biográficos sobre personas anónimas que protagonizan noticias normalmente no relacionadas con la familia ni con la monoparentalidad;

b) Familia: antiguos y nuevos modelos de familia, así como sus problemáticas específicas;

c) Sociedad: aspectos y cambios producidos en las modernas sociedades occidentales (leyes, instituciones, costumbres, valores y creencias, relaciones personales y sociales, etc.); impacto de la inmigración en la diversificación de las estructuras familiares; fenómenos demográficos destacables;

d) Política: respuesta institucional a los problemas específicos de este tipo de familias, inclusión o no de propuestas de conciliación y de medidas fiscales, laborales, sanitarias o educativas en los programas electorales de los partidos;

e) Política social: (in)existencia de redes de apoyo vertical (prestaciones y políticas públicas) dirigidas a los núcleos monoparentales;

f) Religión: postura de las principales religiones occidentales ante formas de familia no convencionales; 
g) Economía: efectos de la crisis económica en las familias monoparentales a cargo de una mujer, en España y a nivel internacional; desempleo, pobreza y exclusión social, colectivos marginales, etc.;

h) Caridad:10 donativos para familias con dificultades económicas, familias monoparentales en casas de caridad, trabajo de ONGs por este colectivo;

i) Ciencia: nuevas técnicas de reproducción asistida y preservación de la fertilidad;

j) Cultura: presencia de la monoparentalidad en manifestaciones culturales y artísticas como pintura, música, fotografía, etc.

k) Ficción: ${ }^{11}$ cine, series, programas de televisión (reality shows); programaciones de televisión y carteleras de cine.

Presentamos a continuación la tabla de frecuencias de las cinco lexías seleccionadas en el corpus de prensa creado ad hoc para nuestros fines:

\begin{tabular}{|l|c|c|c|c|c|c|c|c|c|c|c|c|c|c|c|c|c|c|c|c|c|}
\hline & \multicolumn{10}{|c|}{ Madre(s) soltera (s) } & \multicolumn{2}{|c|}{$\begin{array}{c}\text { Madre(s) soltera(s) } \\
\text { por elección }\end{array}$} & \multicolumn{3}{c|}{ Madre(s) sola(s) } & \multicolumn{3}{c|}{$\begin{array}{c}\text { Madre(s) sola(s) } \\
\text { por elección }\end{array}$} & \multicolumn{3}{c|}{ Madre(s) adolescente(s) } \\
\hline & ABC & EP & EM & LV & ABC & EP & EM & LV & ABC & EP & EM & LV & ABC & EP & EM & LV & ABC & EP & EM & LV \\
\hline 1993 & 52 & - & - & 24 & 0 & - & - & 0 & 1 & - & - & 26 & 0 & - & - & 0 & 1 & - & - & 1 \\
\hline 1994 & 72 & - & - & 38 & 0 & - & - & 0 & 0 & - & - & 22 & 0 & - & - & 0 & 5 & - & - & 1 \\
\hline 2003 & 32 & 1 & 3 & 38 & 0 & 0 & 0 & 0 & 1 & 0 & 1 & 3 & 0 & 0 & 0 & 0 & 5 & 0 & 0 & 1 \\
\hline 2004 & 64 & 5 & 11 & 32 & 0 & 0 & 0 & 0 & 0 & 0 & 0 & 7 & 0 & 0 & 0 & 0 & 4 & 0 & 0 & 0 \\
\hline 2013 & 33 & 85 & 35 & 32 & 1 & 4 & 1 & 1 & 2 & 2 & 1 & 5 & 1 & 0 & 3 & 1 & 10 & 5 & 10 & 5 \\
\hline 2014 & 50 & 81 & 65 & 39 & 0 & 0 & 0 & 0 & 2 & 1 & 1 & 1 & 0 & 0 & 0 & 0 & 4 & 5 & 7 & 1 \\
\hline
\end{tabular}

Tabla 2. Tabla de frecuencias de las cinco lexías seleccionadas en el corpus

Procedemos a interpretar estos datos teniendo presente, además, la clasificación temática de los textos que se esconden tras estas cifras y que, por razones de espacio, no reproducimos aquí. El primer dato que llama la atención es el aumento considerable en el tercer bienio (2013/14) en la frecuencia de la lexía madre(s) soltera(s) -a partir de ahora MS- en dos de los diarios seleccionados, EP y EM.

Analizando los textos correspondientes a esos años en EM, observamos que, mientras en 2003/04 las escasas apariciones de la lexía se producían en textos relacionados con la vida de personajes famosos ${ }^{12}$ y con casos de sociedad más o menos sonados, ${ }^{13}$ en la década siguiente (2013/14) no solo se produce un incremento del número de noticias en estos dos ámbitos (de 3 a 34 en biografías de famosos, ${ }^{14}$ de 9 a 20 en sociedad), ${ }^{15}$ sino también una clara diversificación de categorías temáticas donde se trata la monoparentalidad femenina:

a) Economía (8): MS como víctimas de desahucios, desnutrición en hijos de MS, etc.; 
b) Familia (7): nuevos modelos de hogares y de familias, coste de ser madre sin pareja masculina, recortes en sanidad pública para reproducción asistida de MS y lesbianas, etc.;

c) Religión (5): sacramento del bautismo para hijos de MS por parte del papa Francisco, pastoral de misericordia para los que están en situación de irregularidad canónica, etc.;

d) Caridad (4): cambio de perfil de los beneficiarios de las casas de caridad, que pasa de las habituales MS a familias biparentales, etc.;

e) Ciencia (1): criopreservación de ovocitos, adopción de embriones congelados, etc.;

f) Política social (4): ayudas a madres solteras en Reino Unido y Estados Unidos, incubadoras sociales, etc.;

g) Biografías anónimas (9), ficción (7), cultura (1), política (1).

En el caso de EP, se da una coincidencia parcial con EM, ya que parte de las escasas apariciones del sintagma en el bienio 2003/04 se produce en biografías de famosos y sociedad, ${ }^{16}$, aunque también surge en textos de economía ${ }^{17}$ y otros específicos sobre la familia. ${ }^{18} \mathrm{Al}$ crecimiento espectacular del número de textos en estos ámbitos en el bienio 2013/14 (de 1 a 42 en biografía de famosos, ${ }^{19}$ de 3 a 30 en sociedad, ${ }^{20}$ de 1 a 20 en economía, ${ }^{21}$ de 1 a 9 en familia ${ }^{22}$ ) se suma la aparición de otros campos temáticos donde la monoparentalidad femenina es objeto de interés:

a) Caridad (7): MS como beneficiarias de pisos de caridad, usuarias de comedores sociales, cambio en el perfil tradicional del solicitante de los servicios de casas de caridad;

b) Religión (6): bautismo a hijos de MS, choque entre la doctrina y la realidad social de la Iglesia católica, católicos que no comulgan con la doctrina de la Iglesia sobre las familias;

c) Política social (4): ayudas económicas a MS en EE.UU., empresario español galardonado por la visión social de su empresa;

d) Política (3): MS como posibles votantes de los demócratas en EE.UU. o del partido UKIP en Reino Unido;

e) Biografías anónimas (23), ficción (21), cultura (1).

La mayor variedad temática detectada en este bienio con respecto al anterior no impide detectar una asociación todavía considerable entre monoparentalidad femenina y situaciones de necesidad social y marginación, debidas, en gran medida, a la crisis económica vivida en los primeros años de este siglo XXI. En este sentido, detectamos frecuentes concurrencias de nuestra lexía con determinadas estructuras lingüísticas y elementos léxicos, sobre todo en aquellos textos publicados en las secciones de economía, política social y caridad (sustantivos como paro, ocupas, desahucios, desnutrición, supervivencia, exclusión social, ayudas, caridad, vergüenza, estigma, pederastia o adjetivos en grado positivo o comparativo como enferma, vulnerables o peor): 
1) "La mujer, de 22 años, ha añadido a los agentes que fue un embarazo no deseado fruto de una aventura de una noche y que no pudo en su día abortar ni ahora hacer frente al estigma de ser una madre soltera" (EM, 29/05/2013);

2) "la Asociación Solidaridad con Madres Solteras [...] que ha lanzado un plan este verano para alimentar a los niños españoles en riesgo de exclusión social" (EM, 15/07/2014);

3) "Elsa Tobeña, enferma de hepatitis C [...] Lo de menos en la biografía de Elsa Tobeña son este ramillete de cosas: que sea madre soltera, que no tenga trabajo" (EM, 21/11/2014);

4) "Otras circunstancias que explican el abandono son sociales -la vergüenza de ser madres solteras" (EP, 13/01/2014);

5) "Una excepción entre la mayoría de las porteadoras, que suelen ser analfabetas, muchas divorciadas, otras abandonadas por sus maridos o, lo que es peor en la cultura marroquí, madres solteras" (EP, 10/04/2014);

6) "que las plantaciones contraten como empleados a grupos sociales considerados vulnerables, como transexuales, madres solteras y recicladores de residuos" (EP, 07/01/2014).

En este mismo bienio no es infrecuente que la lexía aparezca ya vinculada a verbos como conciliar, utilizado en aquellos textos donde se reclama que tanto hombres como mujeres puedan hacer compatibles las diferentes facetas de su vida y que, curiosamente en español, siendo un verbo transitivo, ${ }^{23}$ aparece a menudo sin complemento directo explícito, como ocurre en el ejemplo siguiente:

7) "La Asociación de Madres Solteras organiza colegios de tarde durante el invierno para que las madres solteras que trabajan puedan conciliar y campamentos urbanos durante el verano" (EM, 15/07/2014).

Los diarios que permiten la consulta de sus archivos en la década de los noventa, ABC y LV, mantienen constante el número de apariciones de esta lexía a lo largo de los tres bienios, superando con creces a EP y EM en el bienio 2003/04. Ahora bien, observamos igualmente una evolución en las temáticas tratadas. En ABC, mientras que en los bienios 1993/94 y 2003/04 la ficción (71) y la caridad (45) -principalmente por las peticiones de ayuda a través de la sección 'hoja de la caridad' de Cáritas, propia de un diario de línea católica- ocupan los primeros puestos en número de apariciones de la unidad léxica objeto de nuestro estudio, en 2013/14 son las biografías de famosos (25) las responsables del mayor número de ocurrencias; ${ }^{24}$ por otra parte, es muy notable el descenso en el campo de la caridad (4), pues curiosamente en 2013/14 apenas hay ocurrencias relacionadas con solicitud de donativos para estas familias. En LV, en los tres bienios, la ficción (108) y la sociedad (28) ocupan los primeros puestos en número de ocurrencias, aunque en 2003/04 y 2013/14 irrumpen también con fuerza las biografías de famosos $(31)^{25} \mathrm{y}$, en menor medida, los textos dedicados a la familia (8). ${ }^{26}$

El hecho de que en todas las publicaciones que conforman nuestro corpus el número de ocurrencias crezca de forma tan significativa a lo largo del tiempo, debido a su presencia en noticias relacionadas con famosos, demuestra cómo con los años el fenómeno de la maternidad en solitario ha ido ganando visibilidad gracias a personajes conocidos de los cuales no se oculta una experiencia que han vivido como protagonistas de la maternidad en 
soltería o como hijos de MS. Hemos observado, no obstante, cómo la prensa incluye en este grupo a mujeres que han quedado al frente de su familia tras una separación o divorcio, pero donde la figura paterna existe e interviene activamente en la vida de la progenie. ${ }^{27}$ Este hecho podría considerarse una estrategia discursiva a través de la cual se identifica claramente la maternidad en soltería y el núcleo monoparental, ${ }^{28}$ lo cual nos parece que puede llevar a confusión en la delimitación del concepto de familia monoparental.

Los textos clasificados en este estudio en la categoría 'sociedad' no se pueden desvincular del momento histórico en que fueron publicados: así, como hemos visto, en la década de los noventa se trataban temas que en esos momentos eran de actualidad como, por ejemplo, el aumento de nacimientos de hijos de MS en EE.UU. y los cheques que estas recibían por cada nuevo hijo. Pero incluso en este tipo de noticias es evidente la visión negativa que sobre este colectivo imperaba aún en aquellos años: el ser hijo de MS, por ejemplo, se contaba, junto al alcoholismo y la drogadicción, entre las causas de la mendicidad en los niños; los hijos de MS aparecían entre las víctimas más frecuentes de malos tratos físicos, psíquicos y sexuales; las madres solteras en Estados Unidos se describen frecuentemente como personas que se aprovechan de los subsidios del gobierno; la mayor aceptación social de las MS se contaba entre las causas del descenso en el número de abortos, mientras que el menor número de abandono de bebés se explicaba por la mayor facilidad para abortar y porque "ser madre soltera no está tan mal visto" (LV, 02/o9/1994, p. 14).

En el bienio 2003/04, junto a acontecimientos puntuales que provocan picos en los registros de la lexía (críticas hacia las MS por parte de políticos ${ }^{29}$ o el aumento de MS en Andalucía), detectamos un ligero cambio respecto al bienio anterior -se lanza, por ejemplo, al mercado una muñeca Barbie MS que "ha sabido adaptarse al cambio de los tiempos" (EM, 24/04/2003)- pero se sigue relacionando el modelo monoparental con exclusión social y violencia, con deficiencias en la educación de la progenie e incluyendo a las MS entre las víctimas de acoso sexual o prostitución. Esta vinculación se presenta discursivamente, no solo a través de la inclusión de las lexías en textos informativos (sobre todo noticias) relacionados con los fenómenos anteriormente mencionados, sino mediante la frecuente concurrencia de dichas lexías con sustantivos como problemas, violencia, pobreza, ayudas, víctimas, acoso sexual, prostitución; adjetivos como escaso, homeless, problemática o adverbios como peor:

8) "Sobre el acoso sexual en el trabajo [...], sobre todo mujeres y madres solteras, homosexuales y trabajadores con contratos precarios" (ABC, 18/03/2004);

9) "madres solteras o mujeres divorciadas o separadas, con problemas familiares y económicos y de escasa formación cultural” (EM, 18/05/2004);

10) "una madre soltera educará peor a sus hijos" (EM, 20/07/2004);

11) "aumento de la violencia juvenil [...] hijos de madres solteras, divorcios y hogares monoparentales" (LV, 15/10/2004).

En cuanto a los textos expositivos-descriptivos centrados específicamente en la familia y la organización familiar, son muy escasos en la década de los noventa. De hecho, tan solo en LV hallamos un artículo sobre los modelos de hogar en Cataluña entre 1981 y 1991, en el 
cual se destaca el crecimiento producido en el número de "madres solas con hijos", conformado por MS o por mujeres separadas o divorciadas que viven con sus hijos, mientras que hasta la década de los ochenta ese modelo se correspondía con "la mujer viuda y mayor que convive con el o los hijos mayores de 16 años solteros" (LV, 15/12/1994, p. 30). La prensa deja constancia así de la evolución producida en la sociedad catalana desde el cuarto tipo de monoparentalidad al que aludíamos en la introducción de este trabajo (monoparentalidad vinculada a situaciones sociales) hacia los tipos primero y tercero (monoparentalidad vinculada a la natalidad y a la relación de pareja, respectivamente).

Solo en el bienio 2013/14 observamos un mayor interés por parte de la prensa hacia esta temática, y en concreto, como ya hemos visto, hacia la elección voluntaria de vivir la maternidad en solitario. El compuesto sintagmático madre soltera por elección (MSPE) aparece exclusivamente en el bienio 2013/14 y casi siempre en referencia a la Asociación Madres Solteras por Elección MSPE y a la web creada por Rosa Maestro www.masola.org, principal difusora de este sintagma, aunque también es utilizado para describir la situación de una mujer que ha llegado a la monoparentalidad por voluntad propia: "se estima que las madres solteras por elección han ido en alza en la medida en que ha ocurrido lo mismo con el conjunto de las madres solteras" (LV, o8/06/2013, p. 25). Curiosamente, no aparece este sintagma junto a nombres de famosas que reivindiquen esta nueva opción familiar.

Por otra parte, en este último bienio 2013/14 también hemos detectado que el sintagma madre sola se está utilizando como equivalente semántico de madre sin pareja masculina e incluso es presentado explícitamente así en la prensa: "Ser madre sola o sin pareja masculina [...] tendrá un coste de entre 1.000 y 8.500 euros por intento" (EM, 13/8/2013). Aparece fundamentalmente en textos relacionados con la diversidad de las estructuras familiares actuales: turismo reproductivo, consecuencias de la ausencia paterna en la familia, predominio del modelo de familia con hijo único, etc. Recordemos, en cambio, que en la década de los noventa fue muy utilizado en el diario LV solicitando ayuda económica para este tipo de familias en la sección denominada "ventanal de la caridad".

Cuando se desea resaltar que la maternidad en soltería responde a una decisión personal de la mujer, es posible encontrar asimismo el sintagma madre sola por elección, $3^{\circ}$ utilizado únicamente en el bienio 2013/14, en la mayor parte de los casos en relación con la web www.masola.org, aunque también presentándolas como "nuevas familias monoparentales" ${ }_{11}$ que engloban "a aquellas mujeres que se encontraron con una maternidad biológica no buscada en principio, pero que decidieron asumirlo en solitario desde el inicio, frente a otras salidas posibles [...]. En este último caso, son mujeres que convirtieron una maternidad por azar en una maternidad por decisión" (LV, 8/6/2013, p. 25). E incluso se llega a reflexionar sobre la cuestión terminológica suscitada por esta nueva figura: "La comunidad científica ha decidido reservar para ellas el término madres solas por elección (single mother by choice), para diferenciarlas claramente de quienes no buscaron ser madres a solas, pero se encontraron con esa circunstancia no deseada" (LV, 08/o6/2013, p. 25). Al igual que sucedía con MSPE, tampoco madre sola por elección se asocia en la prensa a personajes famosos, como, en cambio, sí ocurría con madre soltera.

Por último, el análisis de la lexía madre adolescente nos muestra un aumento en el número de ocurrencias en el bienio 2013/14 respecto a años anteriores, debido, sobre todo, a su aparición en textos relacionados con la realidad de estas chicas en América Latina, 
Sudáfrica o Filipinas, con temas sociales (aborto, educación sexual), con caridad y acciones solidarias, y con ficción y biografías de personajes conocidos. Algunas temáticas se repiten en los bienios anteriores (madres adolescentes y aborto, mendicidad y pobreza entre madres adolescentes), aunque en la década de los noventa, además, era frecuente relacionar a los hijos de adolescentes con la violencia durante su infancia o en su futura edad adulta.

\section{CONCLUSIONES}

Nuestro análisis de corpus nos ha permitido constatar una evolución en el uso de los términos referidos a la maternidad en solitario. Se va, así, desde un enfoque basado en la concepción de este modelo familiar como aquel surgido por una ruptura voluntaria o accidental del proyecto familiar, por el nacimiento de hijos fruto de una relación extramatrimonial del padre con una mujer soltera o por desconocimiento de la identidad del padre, hasta la presentación de esta situación como una opción familiar fruto de una decisión libre y voluntaria por parte de la mujer que cumple así su proyecto filial desvinculado de un proyecto de pareja.

En efecto, en dos de los diarios consultados (EM y EP) el número de ocurrencias de las lexías madre(s) soltera(s) y madre(s) soltera(s) por elección es considerablemente superior en el bienio 2013/14 respecto a los bienios anteriores. Ello se debe, en parte, a la mayor visibilidad del fenómeno conseguida gracias, principalmente, a las biografías de personajes conocidos (hijos famosos de madres solteras, mujeres famosas que abiertamente declaran su condición de madres solteras o que hablan sin tapujos sobre su proyecto de maternidad en solitario) y a casos de sociedad muy sonados (bebés robados en España), pero también debido a la repercusión de la crisis económica en este colectivo (desahucios, desnutrición, recortes en los tratamientos de reproducción asistida para mujeres solas y parejas de lesbianas) y a una mayor conciencia sobre la diversificación de modelos familiares (reflejada casi en todos los casos en reportajes y noticias sobre las nuevas familias mono- y homoparentales) o sobre el coste que supone ser madre por elección sin pareja masculina.

Esta evolución se refleja igualmente en la ampliación, a lo largo de los años, del abanico temático en que la alusión a este modelo familiar adquiere relevancia. En efecto, en el diario $\mathrm{ABC}$ la evolución no afecta tanto al número de ocurrencias cuanto al tipo de cuestiones en que estas aparecen: desde la presentación de las madres solteras como protagonistas de ficción televisiva y peticionarias de donativos a través de la hoja de la caridad, en el primer bienio del corpus, hasta su mención como mero dato biográfico de famosos españoles y extranjeros. No es exactamente coincidente lo que ocurre en LV, donde son la ficción y los casos de sociedad los ámbitos temáticos en los que con más frecuencia aparecen las lexías analizadas en los tres bienios.

Si bien es en la década de los noventa cuando resulta más evidente la asociación de la monoparentalidad con exclusión social y con pobreza, al identificar con núcleos familiares pobres los hogares encabezados por viudas, solteras, separadas o divorciadas, observamos un claro repunte en el bienio 2013/14, en el que las madres solteras aparecen como víctimas de desahucios, desempleo, dificultades de acceso a la vivienda, etc. Esta identificación va perdiendo peso cuando la vía de acceso a la monoparentalidad es la elección propia, pues entonces la mayor parte de las veces la mujer dispone de recursos económicos suficientes 
para afrontar este proyecto familiar. Entre la evidente feminización de la pobreza y el hipotético empoderamiento femenino (Jociles et al., 2008, 269), existe un continuum donde se da una gran variedad de situaciones de monoparentalidad femenina.

Idéntica circunstancia se observa en el caso del sintagma madre sola, especialmente frecuente en el bienio 1993/94 por su aparición en las peticiones de ayuda económica publicadas en LV, mientras que en 2013/14 las ocurrencias son muy inferiores y están relacionadas con otras temáticas, entre ellas la monoparentalidad por elección, convirtiendo por tanto el sintagma en sinónimo de madre sola por elección. Este último sintagma, hasta el momento, goza de mucho menos éxito que el de madre soltera por elección; su presencia residual se debe en la práctica totalidad de los casos a la web www.masola.org. La lexía madre adolescente, por último, presenta un mayor número de ocurrencias en los diarios de línea conservadora ( $\mathrm{ABC}$ y LV), casi siempre en relación con situaciones de exclusión social de estas chicas en países desfavorecidos, y con temas sociales y apuntes biográficos en países más desarrollados.

Podemos concluir, por tanto, que la representación de la monoparentalidad como fuente de conflictos sociales en los años noventa pierde fuerza en la primera década del siglo XXI. En la segunda década esta categoría socioideológica reaparece bajo dos formas: por una parte, como grupo social más vulnerable a la crisis económica y -aunque en menor medida- como desencadenante de ciertos problemas sociales (infanticidios, violencia y abusos de diversa índole) en el caso de la monoparentalidad por ruptura de pareja o ausencia accidental del cónyuge, y, por otra parte, como perfil sociodemográfico de mayor estatus que opta libremente por un proyecto de maternidad biológica o de adopción desvinculado de la existencia de una figura paterna conocida. En estos últimos años, por tanto, se observa un movimiento oscilatorio entre la marginación y la respetabilidad de esta figura femenina, mientras que hace tan solo treinta años las mujeres que vivían su maternidad en solitario se contaban entre los grupos de población más expuestos a la pobreza, a la discriminación y al estigma social, con menores posibilidades de ocio y éxito personal y profesional.

La mayor presencia de la monoparentalidad femenina en la prensa española en la última década analizada contribuye, además, a un menor ocultamiento social de este modelo, propiciado en gran parte por la imagen pública de mujeres conocidas, procedentes de los más diversos ámbitos, que admiten haber vivido o estar viviendo esta experiencia familiar, lo cual conduce, en consecuencia, a un mayor reconocimiento de las necesidades y posibles problemáticas de estas familias. Ahora bien, hemos detectado que a esta mayor presencia contribuye también una estrategia discursiva de identificación entre maternidad en soltería y núcleo monoparental, al incluir entre las MS a mujeres separadas con hijos de padres conocidos y que, además, se ocupan activamente de ellos, aunque corresidan solo de forma temporal.

Finalizaremos señalando, como posible proyección del presente estudio, nuestro propósito de ampliar esta primera etapa de la investigación con una perspectiva contrastiva del tratamiento mediático de las diversas formas de monoparentalidad femenina y masculina en la prensa italiana, que permita detectar similitudes y divergencias léxicas, semánticas y pragmáticas entre el español y otra lengua románica en el campo de las relaciones familiares. De tal análisis contrastivo se podrían beneficiar los estudios de traducción, ${ }^{32}$ la enseñanza de español como lengua extranjera, la lexicografía y la 
terminología bilingües. También resultaría sin duda de interés el análisis del tratamiento de ciertas lexías, simples y complejas, en la lexicografía monolingüe y bilingüe, así como en otros géneros textuales diferentes a los manejadas en nuestro corpus (blogs, artículos en prensa especializada, textos legales, médicos, etc.). El uso de herramientas de gestión de corpus nos ayudaría a profundizar, además, en las posibles combinaciones e interrelaciones entre las lexías estudiadas y otras unidades del discurso.

\section{NOTAS}

1 En efecto, y en palabras de Van Dijk (2002, 19), "muchas dimensiones de la sociedad se construyen, al menos parcialmente, con el discurso, como la política, el derecho, la educación o la burocracia".

2 En el año 2015, según la Encuesta Continua de Hogares (ECH-2015) elaborada por el Instituto Nacional de Estadística español, en un 38,5\% de los hogares de madres con hijos la mujer era viuda, en un $36,4 \%$ separada o divorciada, en un $13,1 \%$ soltera y en el $12,1 \%$ casada. Hace ya casi quince años, Viñas Álvarez $(2003,48)$ observaba, en relación con la monoparentalidad por elección, que, al igual que la mujer de los años noventa privaba frecuentemente al hombre de su papel de padre, "ahora asumirá el mismo rol porque la mujer decide excluirlo de su maternidad y desdeñar la constitución de una familia en el sentido tradicional. Es una decisión crítica que merece nuestra atención. Estas mujeres apuestan por una maternidad nueva que desmitifica, transgrede, y, en cierto modo, denuncia el abandono, la impotencia y la frustración que generan los padres ausentes".

3 Hemos considerado importante no excluir a las madres adolescentes del conjunto de familias monoparentales, como ocurre a menudo en los estudios sobre esta modalidad de familia. Y ello porque, aunque teóricamente no son necesariamente mujeres que afronten la experiencia de la maternidad en soltería, en la práctica es una situación frecuente de monoparentalidad, como consta en los informes del INE sobre la composición de los hogares españoles.

4 No faltan los estudios que advierten sobre la poderosa influencia social ejercida por los medios de comunicación en, por ejemplo, la preservación de valores tradicionales como los de la familia patriarcal (Arés Muzio, 1998; Herrera Santi, 2000, 570). Muy numerosas son, asimismo, las investigaciones sobre la representación de la mujer en los medios de comunicación y, especialmente, en la publicidad (Di Cristofaro Longo, 1995; Borello, 1999; Bertini, 2004; Garrido Lora, 2007; Montero, 2011; Ribas y Todolí, 2008; Papakristo, 2014, por mencionar algunos estudios recientes en los ámbitos hispánico e italiano).

5 La hemeroteca de El País permite búsquedas en la edición impresa desde el 4 de mayo de 1976 hasta el 7 de febrero de 2012. A partir de esa fecha los contenidos de la edición impresa y digital coinciden y se puede acceder a ellos hasta el día de la consulta. La dificultad en las búsquedas referidas al periodo 1976-2001 radica en que no existe la posibilidad de buscar en los contenidos por palabras clave, sino que el sistema nos obliga a abrir uno por uno los archivos correspondientes a los 365 días de los años objeto de interés; en efecto, si la búsqueda se realiza por palabras clave, sin especificar una fecha precisa, el sistema lanza resultados sin filtrar por fecha desde el año 2001 hasta la actualidad. De ahí que descartemos la década de los noventa en esta publicación como parte del corpus utilizado.

6 La hemeroteca de El Mundo permite realizar búsquedas avanzadas gratuitas en la versión digital del periódico desde el 1 de enero del año 2000 hasta el día de la consulta, incluyendo en los resultados los suplementos Yodona.com, Gentes y Ocholeguas.com, y permitiendo filtrarlos por sección (cultura, internacional, Loc, televisión, Andalucía, Madrid, etc.). En nuestro corpus no hemos excluido resultados por procedencia de suplementos ni por sección temática o geográfica. 
$7 \quad$ La hemeroteca de La Vanguardia permite búsquedas avanzadas en su versión impresa desde el 1 de enero de 1881 hasta treinta días antes de la fecha de consulta. La posibilidad de descargar las páginas en pdf facilita considerablemente la búsqueda de un término. En nuestro corpus hemos incluido los resultados procedentes de todas las ediciones y suplementos.

8 La búsqueda avanzada del periódico $A B C$ permite búsquedas en su versión impresa desde el 1 de enero de 1891 hasta los quince días previos a la fecha de consulta e incluye las ediciones de Madrid, Sevilla, Córdoba, así como los suplementos Blanco y Negro, Cultural y D7. La posibilidad de descargar las páginas en pdf facilita considerablemente la búsqueda de un término. En nuestro corpus hemos incluido los resultados procedentes de las tres ediciones y de los tres suplementos.

9 Como ya hemos advertido, la década de los noventa solo es consultable con buscador de palabras clave en dos de los periódicos seleccionados ( $\mathrm{LV}$ y $\mathrm{ABC}$ ), por lo que las conclusiones que extraigamos respecto a esa década se limitarán a esas dos publicaciones.

Esta categoría está directamente relacionada con la anterior.

11 Muy interesante nos resulta, en este sentido, un artículo publicado en 2012 en el portal mujerhoy.com, donde se plantean las razones del aumento de madres solteras en los últimos años y donde se recoge la siguiente reflexión sobre cómo influyen en las mujeres americanas los productos de cine y televisión que consumen: "Para los investigadores fue sorprendente la gran cantidad de mujeres que pensaba que era infértil, y por ese motivo no empleaba ningún método anticonceptivo. Ellos lo explican por razones culturales, y aducen, por un lado, a las cientos de imágenes de la cultura pop a las que hemos estado expuestos, especialmente en el cine, con parejas teniendo sexo sin protección y que rara vez se quedan embarazadas". La negrita es de los autores del artículo, disponible en: http://www. mujerhoy.com/ser-madre/embarazo/tantas-madres-solteras-691271082012.html.

12 Principalmente por la entrada de Mette Marit en la familia real noruega.

13 Como, por ejemplo, la polémica desatada por las feroces críticas del comisario europeo Rocco Buttiglione contra las MS.

Casos conocidos como los de Paula Vázquez, Whoopi Goldberg o Julieta Venegas.

15 Principalmente con noticias sobre el tráfico de bebés en conventos irlandeses en la primera mitad del siglo XX.

16 Coincidentes en gran parte con las noticias de EM (crítica a las madres solteras por parte de Rocco Buttiglione).

Por ejemplo, sobre los préstamos nacimiento concedidos por el BBVA en 2004.

18 En concreto, la noticia del primer caso de maternidad legal para una pareja de lesbianas en España.

19 Gracias a casos muy conocidos de maternidad en solitario como los de Mónica Cruz, J. K. Rowling o la madre de Barack Obama.

20 Debido, sobre todo, a las noticias sobre los bebés robados entre 1940 y 1990 en España y a las que se refieren a la discriminación que sufren las madres solteras en países latinoamericanos y en la cultura musulmana.

21 MS como víctimas de desahucios y de recortes en ayudas escolares; MS okupas; pobreza entre MS en EE.UU., Latinoamérica y Mozambique; y relación entre la crisis en España y la emigración de MS a otros países con mejores posibilidades de futuro. 
La mayor parte centrados en cómo los recortes por la crisis económica han afectado a los servicios de reproducción asistida en la sanidad pública en España.

23 A diferencia de lo que ocurre en otros idiomas como, por ejemplo, en italiano, donde el verbo conciliare exige explicitar el objeto de conciliación: conciliare vita e lavoro.

24 Desde figuras de la política como Alicia Sánchez Camacho, Rachida Dati o Marine Le Pen, hasta artistas como Isadora Duncan o Maya Angelou, pasando por modelos como Esther Cañadas o escritoras como Sue Townsend, J. K. Rowling y Gertrudis Gómez de Avellaneda.

25 Algunos ya mencionados como J. K. Rowling o Mette-Marit, junto con otros nuevos como Jourdan Dunn o Katie Holmes.

26 En 2003/04, algunos de estos textos relacionan la estructura familiar monoparental con la violencia juvenil, otros analizan el papel que desempeñan las abuelas en la educación de los hijos de MS; en 2013/14, en cambio, los temas se ciñen más estrictamente a la monoparentalidad femenina como opción familiar: reportajes sobre madres sin pareja por decisión propia, entrevista al fundador del primer banco de semen, noticias sobre la caída de las adopciones por parte de mujeres solas y sobre la cada vez más avanzada edad con que las mujeres acuden a la reproducción asistida.

Esto ocurre en casos como el de Katie Holmes, exmujer del actor Tom Cruise.

En algunos pocos casos, además, la lexía aparece, no porque el personaje sea cabeza de familia monoparental, sino porque participa en eventos solidarios relacionados con estas familias o porque para su vida diaria o su profesión (actrices sobre todo) se inspiran en ellas.

29 Muy polémicas resultaron las declaraciones del comisario europeo designado de Justicia, Libertad y Seguridad, Rocco Buttiglione, a las que ya hemos aludido en este trabajo, quien afirmó que «los niños que sólo tienen una madre y no tienen padre "son hijos de una madre no muy buena"» (LV, 17/10/2004, p. 11).

30 Las variantes madres solas por convicción y madres a solas por elección han sido utilizadas, respectivamente, en LV (20/4/2003) y LV (8/6/2013).

31 "Nuevas familias monoparentales, madres solas por elección" es el nombre del estudio realizado en 2013 por IVI Sevilla y la Universidad de Sevilla (equipo de investigación encabezado por M. del Mar González).

32 Los sitios web de numerosas clínicas de fertilidad españolas aparecen traducidos a otros idiomas dado el alto número de pacientes extranjeros que acuden a ellas para recibir tratamiento, sobre todo procedentes de países donde la legislación es mucho más restrictiva, como, por ejemplo, Italia (fenómeno conocido coloquialmente como turismo reproductivo).

\section{REFERENCIAS BIBLIOGRÁFICAS}

ARÉS MUZIO, P. 1998. “Abriendo las puertas a las familias del 2000”, en Arés Muzio, P. (ed.), Hogar dulce hogar ¿mito o realidad? La Habana: Facultad de Psicología de la Universidad, 18-36.

BERTINI, S. 2004. "L’immagine della donna nei media”, en Bertini, S., Bulgarelli, D., y Pitasi, A. (eds.), Saper comunicare. Nápoles: Scriptaweb.

BORELLO, E. 1999. "Pubblicità e piacere: la comunicazione seduttiva”, en Regosa, M. (ed.), Immagini del piacere. Florencia: Alinea, 33-54. 
DI CRISTOFARO LONGO, G. (ed.). 1995. La disparità virtuale. Donne e mass media: analisi di una realtà tra rotture e resistenze culturali. Roma: Armando Editore.

FLORES ACUÑA, E. 2017. "Nuevos modelos de familia y léxico español actual”, Tonos Digital, 32, 1-39.

GARRIDO LORA, M. 2007. "Estereotipos de género en la publicidad. La creatividad en la encrucijada sociológica", Revista Creatividad y Sociedad, 11, 53-71.

HAYS, S. 1996. The Cultural Contradictions of Motherhood. New Haven, Londres: Yale University Press.

HERRERA SANTI, P. 2000. "Rol de género y funcionamiento familiar", Revista Cubana de Medicina General Integral, 16, 6, 568-573.

INSTITUTO NACIONAL DE ESTADÍSTICA. 2015. Encuesta Continua de Hogares. Disponible en: http://www.ine.es/inebaseDYN/ech30274/ech_inicio.htm

JOCILES, M. I., RIVAS, A. M., MONCÓ, B., VILLAMIL, F., y DÍAZ, P. 2008. "Una reflexión crítica sobre la monoparentalidad: el caso de las madres solteras por elección”, Portularia, VIII(1), 265-274.

MEDINA BRAVO, P., FIGUERAS-MAZ, M. y GÓMEZ-PUERTAS, L. 2014. "El ideal de madre en el siglo XXI. La representación de la maternidad en las revistas de familia”, Estudios sobre el Mensaje Periodístico, 20(1), 487-504.

MILKIE, M. A. y DENNY, K. E. 2014. "Changes in the Cultural Model of Father Involvement: Descriptions of Benefits to Fathers, Children, and Mothers in Parent's Magazine, 19962006", Journal of Family Issues, 35(2), 223-253.

MONTERO, M. 2011. "Mujer, publicidad y consumo en España. Una aproximación diacrónica”, Anagramas, 9(18), 83-92.

PAPAKRISTO P. C. 2014. "Strega o madonna: l'immagine della donna nella pubblicità italiana", en Sobrero, R. (ed.), Quando la comunicazione è attenta al genere. Vol. 1. Milán: Collana Comunicazione Sociale, 67-69.

RIBAS, M. y TODOLÍ., J. 2008. "La metáfora de la mujer objeto y su reiteración en la publicidad”, Discurso \& Sociedad, 2(1), 153-169.

RODRÍGUEZ BARCIA, S. 2014. "La construcción discursiva de los roles de hombre y mujer en las revistas de familia”, Razón y Palabra, 18(2), 434-451.

VAN DIJK, T. A. 1999. "El análisis crítico del discurso", Anthropos, 186, 23-36.

VAN DIJK, T. A. 2002. "El análisis crítico del discurso y el pensamiento social", Athenea Digital, 1, 18-24.

VAN DIJK, T. A. 2003. "La multidisciplinaridad del análisis crítico del discurso: un alegato a favor de la diversidad”, en Wodak, R. y Meyer, M. (eds.), Métodos de análisis crítico del discurso. Barcelona: Gedisa, 143-177.

VIÑAS, D. 2003. "Nuevos modelos de maternidad", en VI Trobada de Comares de la Comunitat Valenciana. Qualitat per a la dona davant el nou mil.lenni. Valencia: Generalitat Valenciana, 41-51. Disponible en: http://publicaciones.san.gva.es/ publicaciones/documentos/V.2369-2003.pdf

\section{CORPUS ELECTRÓNICO (PRENSA DIGITAL)}

Hemeroteca $A B C$. Disponible en: http://hemeroteca.abc.es/avanzada.stm

Hemeroteca El Mundo. Disponible en: http://ariadna.elmundo.es/buscador/buscador_ elmundo_avanzado.html?as $=1$

Hemeroteca El País. Disponible en: http://elpais.com/diario/ 
Hemeroteca La Vanguardia. Disponible en: http://www.lavanguardia.com/hemeroteca/ index.html

\section{NOTA SOBRE LA AUTORA}

Estefanía Flores Acuña es profesora Titular en el área de Filología Italiana de la Universidad Pablo de Olavide, España. 